\title{
7
}

\section{A Priori Testimony Revisited}

\author{
Anna-Sara Malmgren
}

Let 'A Priori Testimony' be the thesis, introduced and defended by Tyler Burge (1993, 1997, 1999), that there's a priori knowledge by testimony - more precisely: that at least some of our actual testimonial knowledge is a priori. How does Burge argue this? In large part, by giving a positive account of testimonial warrant and knowledge that sustains it: an account that implies the thesis, and purports to explain how it could be true. Burge's case for A Priori Testimony, then, rests heavily on the plausibility of his positive account.

In previous work, I contested the plausibility of that account (Malmgren 2006). One of the problems I identified is specific to it; one is more general-it arises, it seems, on any model of the epistemology of testimony on which A Priori Testimony comes out true.

Ram Neta has recently responded to the part of my criticism that targets Burge's account in particular (Neta 2010). In this chapter I argue that Neta's response is inadequate. I also explore my second, more general, criticism a little further, and I discuss the prospects for vindicating A Priori Testimony in a different way-a way that, at least at first sight, looks more promising than Burge's: with appeal to (what I call) the 'Fast Track Model' of testimony. I argue that this strategy faces difficult challenges of its own.

The chapter is organized as follows: in $§ 1$, I restate the key components of Burge's account. In $\S 2$, I summarize - and further clarify-my previous objections to it. In $\S 3$, I reply to Neta. In $\S 4$, I consider a few other possible counter-arguments, and I introduce and examine the Fast Track Model.

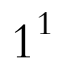

\subsection{The Proof Case}

Two suggestive analogies may explain why A Priori Testimony even seems worth taking seriously; here, let me just mention one: the analogy with relatively uncontroversial cases of 'perception-triggered' a priori warrant or knowledge—cases where such warrant or knowledge is acquired by means of diagrams, formulae, or proofs (cf. 1993, 
480; 1997, 37). ${ }^{2}$ Your specific perceptual experience of, say, a written representation of a certain logical proof may help you access a warrant - an independently existing, a priori warrant-for believing a certain theorem; perhaps a warrant that you wouldn't, even couldn't, otherwise come to have. The experience can do this without (as it were) contaminating the a priori status of that warrant. If the warrant is strong enough, and other things are equal, you may even come to know the theorem-a priori-as a result.

This kind of case provides one of the clearest illustrations there are, of the triggering, merely causal, or warrant-enabling role-as opposed to the justifying, or warrantconferring role- of perception. It's hard to give a principled account of the distinction between these two roles, but at least we have a paradigm, in cases like this - a paradigm that we think we understand. ${ }^{3}$ By assimilating the acquisition of testimonial warrant and knowledge to this paradigm, Burge may tempt us to think that we understand how it, too, could be a priori. Perhaps the perceptual states and processes that are involved in the production (or sustenance) of testimonial beliefs only play a triggering role, in at least some cases: they just facilitate our access to independently existing, a priori warrants. It's a suggestive thought.

In the end, Burge's model of the epistemology of testimony doesn't quite back up the suggestive thought (that certain testimony cases are like that). As we will see, there's a sense in which the model 'gives us more than we bargained for'-if what we bargained for was that thought. The admission that specific perceptual experiences can play a triggering role, in cases like that of the proof, doesn't commit us to expanding the domain of the a priori beyond standard limits. (Indeed, it's compatible with highly restrictive conceptions of that domain—say, as including only analytically true propositions.) On Burge's account of testimony, however, the domain is radically expanded. Granted: the domain of a priori knowledge stays the same. But the domain of a priori warrant now includes that zebras are larger than red poppies, that Bettie likes chocolate cake, that many children have imaginary friends - and any number of other, 'deeply' contingent, propositions (cf. Evans 1985). This isn't yet an objection to the view, but it's worth taking note of.

\subsection{Burge's account}

Burge is a pluralist about epistemic warrant: he holds that it comes in (at least) two varieties. 'Justification' is necessarily cognitively accessible to the agent-perhaps even as such: as warrant—whereas 'entitlement' needn't be (1993, 458-9; 2003, 504). ${ }^{4}$ The a priori/a posteriori distinction applies to both types of warrant, and a warrant is a priori if "neither sense experience nor perceptual belief constitute nor enhance its [warranting] force" $(1997,21)$. Knowledge is a priori, in turn, when it's "underwritten by an a priori justification or entitlement that needs no further justification or entitlement to make it knowledge" $(1993,458)$. And warrant or knowledge that's not a priori is a posteriori. Burge also holds that at least some a priori warrant and knowledge is empirically defeasible (1993, 460-1). As will emerge, two warrants of this type-two 
a priori, empirically defeasible, warrants - take center stage in his vindication of A Priori Testimony: the recipient's default pro tanto entitlements to 'rely on her understanding', and to 'rely on the rationality of her source'.

In testimony, a propositional content is asserted — or in some other way 'presentedas-true'-by a source, to a recipient. (There may of course be multiple sources and/or recipients, but nothing here turns on this.) As Burge conceives of assertion, it requires a linguistic action-namely the spoken or written utterance of a suitable declarative sentence-but it's unclear whether that goes for all presentations-as-true (or whether, say, the shaking of one's head, or the drawing of a figure in the sand, qualifies in certain circumstances). More generally, it's unclear how broad the category of presentationsas-true is supposed to be: Burge explicitly includes obvious presuppositions and conventional implicatures, but leaves it open how to generalize from there (1993, 482 , fn. 20, 21). For much of what follows, however, we can ignore this complication, and focus on testimonial acts that do involve assertions-assertions that, let's grant Burge, are all expressed by means of declarative sentences. (I'll use 'saying', 'telling' and 'testifying' - in lieu of 'presentation-as-true - as umbrella terms: to designate any communicative act that's a potential source of testimonial warrant and knowledge. ${ }^{6}$

A source may or may not have warrant to believe the content she asserts-if she does, and if her attempt to testify is otherwise successful, that warrant is passed on to the recipient: it's 'preserved' in the testimony $(1993,466,486)$. But it's not required that the source has warrant, and that this warrant is preserved, for the recipient to have warrant - or warranted belief - by that source's testimony. For the recipient to know, the source must have warrant: indeed, she must in turn know (what she asserts) - and in some other way than by testimony. (At least there must be a source with nontestimonial knowledge somewhere down the chain; 1993, 485-6, fn. 24. I'll treat this qualification as understood.) But all it takes, for the recipient to have testimonial warrant, is that her two default pro tanto entitlements are in place: her entitlement to rely on her understanding - henceforth: the ' $\mathrm{u}$-entitlement' — and her entitlement to rely on the rationality of her source-the 'r-entitlement'. And all it takes for those entitlements to be in place is that she lacks (undefeated) defeaters. ${ }^{7}$

The two entitlements can be in place-remain undefeated-even if what the source asserts is distinct from what it seems to the recipient that she asserts. (In such cases, the testimonial warrant is a warrant to believe the 'seeming' content.) On Burge's picture, then, testimonial warrant doesn't require correct identification, by the recipient, of the asserted content: it's compatible with her mishearing or misunderstanding what the source said. In fact, it doesn't even require that a content—any content—is (or was) asserted, by the ostensible source or by anyone else: a vivid enough illusion or hallucination, as of someone saying that $p$, may other things equal yield testimonial warrant to believe that $p(1997,24-6)$.

Testimonial knowledge is more demanding, in these respects as well: it does require there to be a source, and it requires the recipient to correctly identify both content and force of that source's speech-act—say, its being an assertion that $p(1993,480$, fn. 19). It 
doesn't, however, require her to correctly identify the words that figure in the source's utterance. And it's unclear whether it requires her to identify the source (either as her source, or as anything else - under any other mode of presentation). It's also unclear what the precise relation is between the correct identification-or, in Burge's preferred phrase, 'correct understanding'—of a given token speech-act, and the knowledge or warranted belief that a speech-act with that content and force is (or was) performed. We'll return to this.

The two default entitlements form part of the recipient's 'proprietary' warrant to believe a given proposition. As already indicated, they're not only jointly sufficient but individually necessary for (her to have) testimonial warrant; hence they're necessary for testimonial knowledge as well. (In cases where both entitlements are indeed in place, and the source in turn has warrant, the source's warrant and the recipient's proprietary warrant together combine to form the recipient's 'extended' warrant; 1993, 485-6.)

Next, for the recipient to have a priori testimonial warrant or knowledge, her entitlements must not just be in place-they must be a priori. But Burge argues that they're indeed a priori, provided that two further conditions are met: first, the recipient doesn't depend on any empirical defeater-defeaters (for the entitlements to be in place) - either she has no defeaters, or her defeaters are defeated by a priori defeater-defeaters - and, second, her understanding of the target utterance is intellectual (1997, 22).

What's intellectual understanding? Burge tells us that:

$[\ldots]$ it is understanding whose exercise in particular instances does not require in those instances perceptual warrant for the application of what is understood. A first approximation elaboration is that it is conceptual understanding that does not require, in thinking and understanding an intentional content, perceptual warrant for the de re application of some aspect of the content. (1997, 21, italics original)

Elsewhere it's further explicated as understanding that only depends on our "standing linguistic abilities" or "standing linguistic competence" $\left(1999,234\right.$, italics in original). ${ }^{8}$ And Burge takes a very liberal view on what that competence is able to deliver. It doesn't, he grants, suffice to understand utterances of sentences that contain certain context-sensitive expressions: expressions whose understanding (on given occasions of use) require perceptual identification of their referents-paradigmatically: perceptual demonstratives and pure indexicals. Nor does it suffice to recover certain indirect speech-acts: speech-acts that differ in content and/or force from those that constitute the 'default readings' of the uttered sentences-paradigmatically: conversational implicatures (1993, 483; 1997, 22; 1999, 234, 245). But, with these two caveats, Burge claims that " $[t]$ he standing mechanism yields an enormous amount of understanding" (1999, 235).

Importantly, it doesn't just yield understanding of content, but also, frequently, of force (1993, 482; 1997, 22, 44, fn. 3). In particular, our understanding of assertoric force is frequently intellectual. That, we're told, is because there's a 'conceptual connection' 
between assertoric force and declarative mood $(1993,482)$. And keep in mind that what's at issue here isn't just our understanding of sentence-types-but of specific dated utterances (or sentence-tokens). The claim is that your grasp of both content and force of the speech-act expressed by a specific dated utterance of, say, 'zebras are larger than red poppies' may well be intellectual—-that your standing linguistic competence may suffice to identify that particular speech-act as an assertion that zebras are larger than red poppies. (This example is Burge's own; 1997, 22.) Likewise-I presume-for your understanding of a specific dated utterance of, say, ' 16 x $78=1248$ ', 'Norway was occupied during WWII', 'Bettie likes chocolate cake', or 'many children have imaginary friends.'

For concreteness, let ' $A R$ ' (for 'a priori recipient') be a recipient who has what it takes to be a priori u-entitled, and a priori r-entitled: $A R$ 's understanding of her source's utterance (or apparent utterance, or apparent source's utterance ...) is intellectual, and $A R$ has no undefeated or empirically defeated defeaters. Note that that's already enough to ensure that $A R$ has some a priori warrant to believe the content of that utterance-say, that Bettie likes chocolate cake. Whether $A R$ has all-thingsconsidered a priori warrant partly depends on the status of the (eventual) warrant that is passed on from her source. It also depends on the status of $A R$ 's supplementary warrant, if any: if $A R$ has no supplementary warrant (to believe that content), or if she does but it's a priori as well, the status of $A R$ 's all-things-considered warrant is a priori. But if $A R$ has a posteriori supplementary warrant, then, of course, her all-thingsconsidered warrant is a posteriori too.

Suppose $A R$ falls in the first mentioned category: she has no supplementary warrant at all to believe that Bettie likes chocolate cake. Then the only remaining variable is the status of her source's warrant: if the source has a posteriori warrant, then, again, $A R$ 's all-things-considered warrant is a posteriori. But if the source has a priori warrant, $A R$ is in the clear: her all-things-considered warrant is a priori. Likewise if the source has no warrant-in that case too, $A R$ is in the clear, since her all-things-considered warrant is exhausted by her default a priori entitlements.

Thus there are-crudely put - at least two different ways to come by all-thingsconsidered a priori warrant by testimony: one is to use a source with a priori warrant; another is to use a source without warrant. (A third is to use a merely apparent source, and/or a merely apparent utterance, since, in such cases too, no warrant at all-hence no a posteriori warrant-is preserved in the testimony.) But, Burge tells us, there's only one way to come by a priori knowledge by testimony: for that, one needs a source who herself has - not just warrant, or even a priori warrant - but a priori knowledge of the content in question: a priori knowledge that's not, in turn, testimonial $(1993,486-7){ }^{9}$

$A R$ has a priori knowledge by testimony, then, just in case there's indeed a source, the content that $A R$ takes that source to assert is the very same content that the source asserts, and the source has a priori, non-testimonial knowledge of that content. The first two conditions, recall, are requirements on testimonial knowledge in general. And the third condition has an interesting consequence: that what we can know a priori by 
testimony comes apart from what we can have a priori testimonial warrant to believe (cf. 1997, 44 fn. 2). Presumably, our sample content is a case in point: that Bettie likes chocolate cake can't be known a priori by testimony, since it can't be known a priori in any other - any non-testimonial - way. So, given that this is by hypothesis the content that's at issue here, $A R$ doesn't have a priori testimonial knowledge, however else we fill out the details of the case. At most $A R$ has all-things-considered a priori (doxastic) warrant.

But the immediate focus in what follows is on warrant-not knowledge. If, as I maintain, it's not even possible to be in $A R$ 's shoes,${ }^{10}$ then, of course, it's not possible to have a priori knowledge by testimony.

\section{2}

\subsection{Objections (first round)}

In Malmgren 2006, I argued that there's no plausible conception, available to Burge, of the object of the first default entitlement-no plausible answer to the question "what does the u-entitlement entitle the recipient to do?" My argument was, in effect, an argument by elimination: I considered every (at least minimally feasible) candidate answer I could think of, and criticized each in turn (Malmgren 2006, 212-24). Two of the candidates will be repeated shortly.

Next, I argued that Burge fails to accommodate the presumption that our knowledge of what's said ('of the specific type') — say, your knowledge that Max just said that Bettie likes chocolate cake-plays an epistemic role, vis-à-vis our testimonial knowledge, and that the failure to do so commits him to a peculiar picture of the recipient's motivational psychology (Malmgren 2006, 224-30). (But the fundamental point concerns warranted belief-not knowledge. See below.) The second objection is largely independent of the first. It's also more general-on the face of it, it arises on any account that sustains A Priori Testimony.

Burge is clear about what the recipient's second default entitlement-the r-entitlement - is a warrant to do (Burge 1993, 467-73; 1997, 21): it's a warrant to accept as true the content of an arbitrary source's assertion (or apparent assertion, etc. ${ }^{11}$ ). More simply: it's a warrant for her to believe what she was told, by a given source on a given occasion-say, that Bettie likes chocolate cake. That the recipient must have warrant to believe that content, in order to have testimonial warrant/knowledge, is obviously not controversial. It's not controversial since that's precisely the content she has testimonial warrant to believe, or testimonial knowledge of, if she does. ${ }^{12}$

It's tempting to suppose that the first default entitlement-the u-entitlement-is likewise a warrant for the recipient to believe something; specifically: a warrant to believe that the given content is (or was) indeed asserted, by the given source on the given occasion. It's tempting to suppose so, because it's independent plausible that 
testimonial warrant and knowledge requires warrant to believe a claim of this sortroughly: that you can't have testimonial warrant to believe what you were told (say, that Bettie likes chocolate cake) unless you have warrant to believe that you were told it, by so-and-so then-and-there (say, that Max just said that Bettie likes chocolate cake). So this interpretation makes sense of the alleged necessity of the u-entitlement. It also looks - in at least some places-like it captures Burge's intent (e.g. Burge 1993, 476; 1999, 235).

The main problem is that it's very hard to see how, if this reading were correct, the u-entitlement could ever be a priori: how anyone, otherwise relevantly like us (cf. footnote 10), could have a priori warrant for believing a content such as that Max just said that Bettie likes chocolate cake. On the face of it, this is no more plausible when, by Burge's criteria, the target utterance is capable of being intellectually understood, than when it isn't (cf. Malmgren 2006, 216-17). And note that the point doesn't rest on any demanding conceptual requirements on believing - and, derivatively, on having warrant to believe- the content in question: requirements to the effect that one be able to refer to the time and place of the given assertion under any other mode of presentation than, say, sometime recently someplace not too far away, or right here now, or refer to the source under any other mode of presentation than, say, my source, or the speaker, or whoever wrote this book.

Another option-perhaps, in the end, Burge's preferred option - is that what the uentitlement entitles the recipient to do is to believe that the given content is (or was) asserted by some source or other, at some point or other. More simply: to believe that she was told it, but without any commitment at all as to where, when and by whom-say, that someone or other, at some point or other, and in some way or other, said that Bettie likes chocolate cake. (Cf. "What one is entitled to on intellectual grounds is merely, prima facie, that a given content is presented as true. One gets nothing about the time, form, or circumstances of the assertion" Burge 1993, 483; second emphasis added.)

However, this suggestion is hardly an improvement on the first: it's no easier to see how anyone could have a priori warrant to believe a content about what's said of thisless 'committal' or specific - type, than to believe a content about what's said of the more specific type. There are of course several ways, easily available to a typical recipient of testimony, to come by warrant to believe it - perhaps most obviously: by competent deductive inference from (warranted belief in) a content of the more specific type-but none that, it seems, would or could deliver a priori warrant for her to believe it. ${ }^{13}$

The problem here isn't, or not just, that Burge himself fails to give an adequate explanation of how the testimonial recipient could have a priori warrant to believe what — on either of these readings—she sometimes, supposedly, has a priori warrant to believe. (Although that, too, is the case in my view. ${ }^{14}$ ) It's that there is no adequate explanation in the offing: indeed, we don't even know how to begin to explain what needs explaining. That, at any rate, is what I argued in my previous piece (Malmgren 215-17). 
But, as we'll see, this is the point at which I'm being challenged by Neta. According to him, I overlook ${ }^{15}$ a 'perfectly good' explanation of how it's possible for a recipient to have a priori warrant to believe a content about what's said of the less specific typeschematically: that someone at some point said that $p .{ }^{16}$

\subsection{Objections (second round)}

Let a 'successful recipient' be an agent who at least has doxastic testimonial warrant: an agent who is warranted in believing, and/or knows, that $p$ by testimony. My second objection to Burge starts with the thought that any such agent is (also) warranted in believing a content about what's said of the more specific type-schematically: that her source said that $p .{ }^{17}$ But her warrant for believing that her source said that $p$ is inevitably a posteriori.

The next step is that the successful recipient's warranted belief that her source said that $p$ plays a causal-explanatory role in the formation of her testimonial belief that $p$. More simply put: that she believes what she's been told at least in part because she believes that she's been told it, by so-and-so then-and-there. ${ }^{18}$

Third, her belief that her source said that $p$ isn't 'any old cause': it has the right kind of content to provide her with a (good, pro tanto) reason-a warrant, or partial warrant - to believe that $p$. There's obviously no deductive relationship between the contents of these two beliefs, but I take it that that's not required for a proposition to be a reason to believe another. And, for all I've said, there are numerous contexts where the content that her source said that $p$ isn't a reason (or is a fully defeated reason) for a given agent to believe that $p$-but when that agent is a successful recipient, with respect to $p$, she's in a context where it is a reason. ${ }^{19}$

Fourth: that her source said that $p$ is a reason that the successful recipient has: it's a reason of hers to believe that $p$. Perhaps the fact that she believes it, or that she has warrant to do so, is already enough to ensure this. But it also comes out true on more stringent views of what it takes to have a reason: views that require warranted belief. (If she knows what's said, it comes out on even more stringent views. ${ }^{20}$ )

A natural way to pull all of this together is by saying that the proposition that her source said that $p$ is among the successful recipient's reasons for believing that $p$-her operative reasons: the reasons-for-which she believes that $p$-or, equivalently, that her belief that $p$ is at least partly based on her belief that the source said that $p$. This, of course, fits nicely with the observation that a typical recipient, if she's the least reflective, may well cite the fact that her source said that $p$ as her reason, or one of her reasons, for believing that $p$ - say, she may respond that Max just told her so, when asked how she knows that Bettie likes chocolate cake (or why, for what reason, or on what grounds, she believes it). On this way of pulling things together, she simply comes out right.

But Burge can't avail himself of this, natural picture: it's in tension with A Priori Testimony. If the recipient's belief that $p$ is based on her empirically warranted belief that her source said that $p$, then her belief that $p$ is empirically warranted too (hence, at 
best, constitutes a posteriori knowledge). So Burge had better deny that her one belief is based on the other-or, at least: deny that that's the case across the board.

One option here is to grant that what I called the 'natural picture' accurately captures the motivational psychology of the canonical or typical (successful) recipient, but argue that there are exceptions: that at least some successful recipients-importantly: recipients whose testimonial beliefs constitute knowledge-differ from the norm in this respect. Another option is to deny that the natural picture captures the structure of the typical—or even any! — successful recipients' reasons and beliefs.

Either way, however, Burge is now in an uncomfortable spot. Take a specific, successful recipient whose belief that her source said that $p$ is a cause of her (warranted) belief that $p$, and provides a reason for her to believe that $p$ - a recipient who has that reason, but whose belief that $p$ isn't based on her belief that her source said that $p$. What's the explanation? Why is her testimonial belief not based on her belief about what's said? Burge — and, more generally, the A Priori Testimony advocate-owes us an answer to this question. Let me clarify why it's a difficult burden to discharge.

The case as described is structurally similar to the familiar counter-examplesabundant in the literature - to a straightforward causal analysis of the basing-relation (and/or of operative reasons): cases of 'reason-independent causation.' Various competing diagnoses have been offered of what exactly goes on, or goes wrong, in cases like these-cases where a suitable belief (or other intentional state) figures in the causal explanation of another belief (or other state, or action) without being part of its base. One broad family of diagnoses appeal to the notion of deviant causation; another family introduces further, or substitute, conditions on basing. ${ }^{21}$

My challenge to the advocate of A Priori Testimony isn't just a challenge to take a stand in this debate; that would be relatively uninteresting - not because the debate concerns an uninteresting problem, but because it concerns a problem that, at least on the face of it, can be expected to have a solution. Rather, the challenge is to make good on the claim that some cases of testimony-indeed, of testimonial knowledge- are cases of reason-independent causation, whatever the correct analysis of that phenomenon is. The assimilation has little face-value appeal, as a quick glance at some of the familiar examples should make clear. ${ }^{22}$ And it doesn't increase in appeal on any of the extant, available diagnoses.

Suppose the first broad family of diagnoses-diagnoses that appeal to causal deviance-is on the right track; then, to a first approximation, what makes all the familiar cases cases of reason-independent causation is the presence of some kind of interference mechanism: a mechanism that interferes with a salient subset of the agent's normal causal-psychological processes, and that's crucially involved in the production of the featured effect. ${ }^{23}$ In this framework, the suggestion - the suggestion in need of further defense-would be that some such mechanism (or set of mechanisms) is involved, across the relevant range of testimony cases: an interference mechanism that explains why the recipient's belief that $p$ isn't based on, although caused by, her belief that her source said that $p$-a mechanism that, crucially, doesn't prevent her from knowing that 
$p$ by that source's testimony. What would the mechanism be? At the very least, we need to be provided with more detail. And note that-even at this level of abstraction - the suggestion is quite odd: that a prerequisite for a priori warrant and knowledge by testimony is that the testimonial belief be partly explained by the workings of an interference mechanism. Of course, matters are worse if the scope of the suggestion is typical testimony.

A competing suggestion, belonging to the other family of views, would be that some higher-level requirement or other on basing has been violated: that, in the cases of interest, the recipient lacks the appropriate attitude-perhaps awareness, belief, or warranted belief - to the status of the claim that her source said that $p$ : its being a reason (for her) to believe that $p$. But this suggestion too is, at best, peculiar: that the only recipient who's able to have a priori warrant and knowledge by testimony is the recipient who, loosely put, gets her reasons wrong-who fails to realize that a certain reason to believe that $p$, indeed one of her reasons to believe that $p$, is indeed a reason for her to do so. (Or, if the requisite attitude is warranted belief, who fails to rationally realize this: who lacks warrant altogether to believe that $p$, or who does have warrant but believes it on other grounds.) And, again, matters are worse if the scope of the suggestion is typical testimony.

Matters are worse if that's the scope since it's very implausible that the typical, successful recipient fits either of the above (minimal, theoretical) descriptions. ${ }^{24}$ At a more intuitive level: it's implausible that that recipient's motivational psychology is relevantly similar to that of agents featured in stock examples of reason-independent causation. The principal problem, however, applies regardless of scope: it's that the suggestion commits us to there being at least some testimonial recipients whose motivational psychology is relevantly similar to that of such agents-but who nevertheless know the target proposition (by testimony). It's by no means obvious how to make good on this suggestion, given that the agents in the stock examples don't even have doxastic warrant (where applicable): their beliefs aren't properly based, and so not warranted, even when all other requirements on warranted belief are met. ${ }^{25}$

I return to these considerations in $\S 4$.

\section{3}

\subsection{Neta's proposal}

Neta doesn't address my second objection (just rehearsed). But he offers an interesting reply to the first - to my objection that Burge has no plausible conception available of the object of the u-entitlement: no good answer to the question what it's a warrant to do.

Neta argues that I'm too quick in rejecting the suggestion that it's a warrant to believe a content about what's said of the less specific type: that someone at some point said that $p$. (Or, in the locution he borrows from Burge: 'that a rational source presented 
is as true that $p^{26}{ }^{26}$ In response to my main complaint about that option, Neta argues as follows:

[w] hat I'd like to focus on is Malmgren's suggestion [...] that we have no way to explain how it is possible for someone to whom it seems that a rational source has presented it as true that $\mathrm{p}$ to be a priori warranted in believing the contingent proposition that a rational source has presented it as true that $\mathrm{p}$. It seems to me that, on the contrary, we have a perfectly good explanation of this, which I'll now outline by means of an example.

Suppose that I present it as true that, say, Washington, DC is the capital of the United States. If I do this under normal circumstances, then, while I might not be a priori warranted in any particular beliefs concerning the medium by which I presented this proposition as true $[\ldots]$, I can at least be a priori, defeasibly warranted in thinking that I have (somehow or other) presented it as true that Washington, DC is the capital of the United States: my warrant for believing this contingent proposition concerning what I have presented as true is of the same sort as my warrant for believing other contingent propositions concerning my communicative intentions, and it is not typically constituted by my sensory or perceptual experiences. It is crucial to recall here that for an agent to present something as true does not require that the agent make any noises or bodily movements: Burge leaves open that an agent can present something as true by means of extra-sensory perception. Indeed, in at least one passage he suggests that judging that $\mathrm{p}$ is a way of presenting it as true that $\mathrm{p}$ : "I use the term 'presentation as true' to cover more than assertions and judgments" (Burge 1993, 482, emphasis added). If this is right, then I can present something to myself as true simply by thinking of it as true, i.e., judging that it is true or otherwise affirming its truth in thought.

Now, if I can be a priori warranted in thinking that I have presented this proposition as true, then I can also be a priori warranted in thinking that I have been given to understand this proposition as true. But the following conditional is a priori: if I have been given to understand something as true, then a rational source (maybe me, maybe another rational source) has given it to be understood as true, or in other words, has presented it as true. (Neta 2010, 209-10, italics in original.)

The passage continues with the attribution of some further reasoning to the (putative) recipient - reasoning that's required on Neta's reconstruction of Burge's account. But there's no need to rehearse that here (and nothing turns on the exegetical disagreement). The quoted passage appears to already contain what I'd asked for: an explanation-or at least an explanation sketch-of how anyone (relevantly like us) could have a priori warrant to believe that someone at some point said that $p$. But is it a plausible sketch? And is it applicable to the case of interest? I'll consider these questions in turn.

On the face of it, the force of Neta's case essentially depends on the fact that the agent who has the a priori warrant is the very same agent who performs the assertion that makes the target claim true (or, at least, that this seems to her to be the case): the same agent whose 'saying'-here: judging - that $p$ makes it true that someone at some point said that $p$. It's because, but only because, she has warrant for believing that she said that $p$, that she has warrant for believing the more general claim. More precisely: the case seems to be a standard case of inferential warrant, where the agent's 
warrant to believe one proposition (here: that someone at some point said that $p$ ) partly rests on, or derives from, her warrant to believe another (here: that she said that $p$ ) -a proposition that's a reason for her to believe the first. On usual assumptions about inferential warrant, her warrant to believe the more general proposition is a priori only if her warrant to believe the more specific proposition is. And, now, it's not implausible that the latter warrant is a priori-provided that introspective warrant is a priori, at least in the case at hand.

So let's grant that it is. To further simplify: let's grant that introspective warrant is a priori across the board, and that one can have such warrant for believing that one is currently 'thinking of $p$ as true' or 'judging that $p .{ }^{, 27}$ (I take these phrases to be equivalent to 'occurrently believing that $p$ '.) If, as Neta suggests, thinking of $p$ as true is just another way of saying that $p$, one thereby has a priori warrant for believing that one is saying that $p$, which transparently entails that someone at some point did. Presumably, this little argument is able to constitute a 'complete' inferential justification; i.e. one doesn't need warrant - a priori or a posteriori-for believing any further propositions, to have warrant for believing its conclusion (given warrant for believing the premise) ${ }^{28}$ But then, if other things are equal, no a posteriori element is introduced, and so our agent - the agent who has (introspective) a priori warrant for believing the premise- has a priori warrant for believing the conclusion too: that someone at some point said that $p$.

It's unclear whether introspection affords any other suitable a priori route to the desired destination. Perhaps it's possible to have introspective warrant to believe that one, just a moment ago, intended to say that $p$. Although intending to say something isn't itself a way of saying it - not even on the present, highly permissive conception of sayings - this, too, could plausibly constitute the first step in an (inferential) warrant to believe that someone at some point said that $p$. What's doubtful, however, is that it could constitute the only step - in particular, that there's a way to 'move' from it, to (warrant to believe) the conclusion, without the benefit of any auxiliary empirical warrant. (E.g. to believe that one usually says what one intends to say? That one frequently did in the past?) The proposed warrant-structure can be elaborated in a variety of ways, consistent with the rationality of the corresponding transition. But it's very controversial that it - in contrast to the previous structure-needs no elaboration at all: that it's complete as it stands. And, on all the obvious ways of elaborating it, the agent has warrant to believe further propositions: warrant that could only be empirical.

Likewise for routes from (introspective warrant to believe) that one now intends to say that $p$, that one remembers that one said that $p$, that one remembers that someone at some point said that $p$, that one believes that someone at some point said that $p$-and so on. ${ }^{29}$ In each case, considerable further work is needed to support the claim that it's possible to rationally move from the suggested starting-point, to the desired end-point, without any auxiliary a posteriori warrant on the agent's part.

As I read it, Neta's example does not introduce this complication. It does however depend on the permissive conception of sayings. But I'll go along with that for now. ${ }^{30}$ 
Next: is the proffered kind of a priori warrant, to believe that someone at some point said that $p$, available to a testimonial recipient-specifically: to a successful recipient, of the testimony that $p$ ? It seems clear that it is. We can stipulate that the character in Neta's case has testimonial knowledge or warrant for believing the target proposition (that Washington, DC, is the capital of the US); on the face of it, that presents no obstacle at all to her also having a priori warrant, of the sort we've sketched, for believing that someone at some point said it.

The crucial question, however, is whether that a priori warrant would or could be explanatory of her testimonial warrant/knowledge: whether it's possible to be a successful recipient of the testimony that $p$ partly because of, or in virtue of, the fact that one has the proffered a priori warrant for believing that someone at some point said this. And the answer to that question seems to be 'no.' Not because we can't testify to ourselves-we can - but, first, because the putative recipient's (a priori) warrant to believe that someone at some point said that $p$ would at best be idle in the explanation: all the work would be done by her (a priori) warrant to believe that she, or her source, said that $p$. Bracketing exegetical concerns, that's all well and good; we could simply regard Neta's proposal as an answer to the question how the u-entitlement could be a priori-if it's a warrant to believe a proposition about what's said of the specific type: that one's source said that $p$. But, second, it's not clear that what would be explained, in the most favorable case, is testimonial warrant or knowledge: it lacks a certain pattern of undermining defeat that's arguably distinctive of testimony.

\subsection{Testifying to oneself}

Suppose you dust off my old diary, and read what I wrote twenty years ago. Presumably you could, by doing so, acquire testimonial knowledge of - or warrant for believing - any number of things about my past. Likewise, it seems, if I dust off my old diary, and read what I wrote back then. I mustn't mistake the diary for a piece of fiction, have doubts or reasons to doubt the author's sincerity, etc. But all of that, of course, goes for you as well (in the scenario where it's you who reads it). The fact that I'm the author doesn't, by itself, seem to make a relevant (negative) difference; nor does it make a difference that — as we may further suppose-I believe, or even know, that I am.

For another prima facie example (of what I'll call 'self-testimony'), consider a case of the familiar sort in which you consult the to-do-list, the recorded message on your phone, or the notes in your agenda, that your past self composed to aid your memory: to help you remember that $p$. On the face of it, there are circumstances where this, too-the consultation of your own reminder-provides you with knowledge or warranted belief that $p$ : knowledge or warrant by (your own) testimony. ${ }^{31}$

There's no need to suppose that the agent, in a case like this, has a priori warrant for believing that someone at some point said that $p$-or, for that matter, that she in particular did. It's perfectly possible that she has some such warrant (on the assumptions made above). But we needn't imagine the example in that way, to make it plausible 
that she has knowledge or warranted belief that $p$, and that that knowledge/warrant is testimonial. It does, indeed, seem necessary to imagine it in such a way that she has warrant—some warrant—-for believing that her source said that $p$. On the obvious reading of the case, however, she has that: she has a posteriori warrant of the usual kind-the kind that's available to potential recipients other than herself. It's a warrant that owes some of its 'justificatory force' to her experience of a specific utterance; here, an utterance made (or apparently made) by her past self. The exact details do not matter.

But perhaps there are other cases - other prima facie instances of warrant or knowledge by self-testimony - in which the corresponding a priori warrant does play a crucial role? Here is a candidate. Suppose you forgot all (external) reminders at home, but that a little introspection reveals that you're thinking of it as true- that you occurrently believethat $p$. (To screen off noise, we may also suppose that you lack salient independent reason to believe that $p$.) Could this, too- the 'inner' consultation of your own beliefresult in knowledge of, or warranted belief, that $p$ ? Could your introspective evidence that you believe that $p$ be a reason for you to (continue) to believe it? It does in fact seem plausible that it could. Of course, various additional requirements must be satisfiedhere, as in the other examples - but even on fairly demanding views of what those requirements are, it looks like the case could be realized in such a way that they're met. ${ }^{32}$ (E.g. perhaps you have, and/or have evidence that you have, an excellent relevant track record, or perhaps $p$ 's truth is part of the best available explanation of why you believe it.)

But would the warrant or knowledge that you'd have, in a suitable realization of the case, be testimonial? (And if not, why not?)

The act of saying, telling, or testifying - the type of communicative act that's supposed to be the source of distinctively testimonial warrant/knowledge-often receives an initial gloss that precludes this: a gloss that stipulates it to involve linguistic or other overt behavior. (Burge is a notable exception here.) Occasionally it's also part of the initial gloss that source and recipient are distinct (and/or take one another to be distinct); if that's correct, even seemingly straightforward examples of self-testimonylike the diary- and reminder-case- are in question. ${ }^{33}$ However, it's unclear whether any such gloss deserves to be treated as final word. Indeed, it's unclear how to approach the matter-what the proper methodology is. I take it that it shouldn't be settled by fiat; substantial issues might hinge on the classification of our three examples (and, more generally, on how we demarcate the target domain). Perhaps the best theoretical framework —our best, future, overall epistemology — will assimilate all three to canonical cases of warrant/knowledge by testimony; perhaps only some, or none. Perhaps it'll offer alternate groupings, depending on the questions asked. (There might, of course, be reasons to close off some options in advance. At present I'm just questioning the advisability of doing it by stipulation.)

So, how to proceed? One approach is to directly investigate the nature or 'metaphysics' of testimony, and of what it is to testify, in abstraction from any epistemological concerns-perhaps by reflecting on a wide range of examples of different communicative acts and behaviors, and consider which of them intuitively count as 
testimony. (There are some attempts at this in the literature. ${ }^{34}$ ) But I doubt that any, suitably general, questions about the metaphysics of testimony are fruitfully pursued in isolation from questions about its epistemology-in particular, that we can make progress with the classification of hard cases in this way. The research project (at least as carried out to date) appears to presuppose that there's a determinate notion of testimony-or, more precisely, of 'natural' or 'informal' testimony (cf. Coady 1992; Lackey 2006) - a notion that we have a firm, independent grasp on, and that maps on to the right domain: testimony as a source of a distinctive type of warrant and knowledge. But why think so? ${ }^{35}$

What I propose, instead, is to focus on paradigm cases of testimonial warrant/ knowledge, and to seize on a notable-recognizably epistemic - feature that they all seem to share: a feature that can be acknowledged without appeal or commitment to any specific theory of the epistemology of testimony. The specific feature that I have in mind is a certain defeater-structure: a characteristic pattern among the first-order considerations that are able to constitute (normative) 'underminers' ${ }^{36}$ On the working hypothesis that this isn't an accident—but that the shared pattern is, or reflects some property that is, part of what sets testimonial warrant/knowledge apart from warrant/ knowledge of other types-we can get a little further with the present issue. ${ }^{37}$

Canonical testimonial warrant and knowledge is potentially undermined by at least three distinct kinds of considerations: evidence that the source is incompetent (e.g. that her belief in the content she asserts is false, and/or unreliably generated or sustained); evidence that she's insincere (e.g. that she's lying or acting); and evidence of relevant communication-failure (e.g. of misperception or misunderstanding, on the recipient's part). These considerations interact in interesting ways, come in varying degrees of generality, and may take somewhat different form, depending on whether it's warrant or knowledge that's at issue-but none of that matters here. ${ }^{38}$ What matters is that, in paradigm cases, warrant and knowledge by testimony is vulnerable to all three, broad varieties of undermining defeat. That shouldn't be controversial: everyone-regardless of their theoretical views on the epistemology of testimony — can agree on it.

Now, it seems clear that this goes for the diary-reader's warrant (or knowledge) as well, in our first prima facie case of self-testimony: her warrant is potentially undermined by evidence of incompetence, insincerity, and communication-failure-even though she is, and/or thinks that she is, her own source. It's not hard to specify what would constitute such evidence, or to describe specific circumstances where her warrant is indeed defeated by it. (Suppose that, on second read, a crucial phrase seems to have been used ironically, or that she recalls a tendency to brag on certain matters in her entries...) Likewise for our second example-where the agent consults her own reminder-and, indeed, for all others I can think of where the putative recipient's warrant to believe that her source said that $p$ is empirical warrant of the usual kind.

The only case that differs is the one that Neta needs: the case where the corresponding warrant is introspective and a priori. Arguably, it doesn't differ with respect to evidence of incompetence, in the (putative) source; here, manifested as evidence that 
some or all of one's introspectively accessible beliefs are, for instance, the product of wishful thinking. But there seems to be no room for defeaters of the second and third variety. Insincerity and communication-failure requires a certain vehicle that just isn't there-nor is rationally taken to be there (with one qualification, to come).

What would count as evidence that the source is (or was) insincere, in testifying that $p$, in the case where ex hypothesis she testifies simply by judging-occurrently believing-that $p$ ? A belief cannot be insincere. It can't even coherently appear insincere (to the first person, or anyone else): only the expression of belief can. Attitudes of other types can misleadingly appear to be beliefs (and conversely) — but evidence that some such possibility is realized isn't yet evidence of insincerity in a belief.

Next, what would count as evidence of relevant communication-failure? Evidence that threatens to defeat (here: undermine or rebut) an agent's introspective warrant to believe that she 'said' that $p .{ }^{39}$ Canonical testimonial warrant/knowledge is vulnerable to defeat by evidence that one, say, misheard or misinterpreted the utterance by which the source said, or seemed to say, that $p$. But, in the case of interest, there is no such utterance; nor is there a gesture, a drawing — or, it seems, any other suitable middleman.

To clarify: the very possibility of relevant communication-failure, here, seems to stand or fall with a certain controversial view of introspection: a view on which our introspective access to (the occurrence, content, and attitude-type of) our mental states is mediated by access to representational vehicles - vehicles that, importantly, require interpretation, by the first person, as well as 'inner' perception (or independent apprehension of some other kind). Otherwise they couldn't be misperceived, misunderstood, or, it seems, admit of any other recognizable form of communication-failure.

That view has very little prima facie plausibility. Of course we sometimes 'think in words' (or, for that matter: in pictures, sounds, or tangibles), but it's unclear whether this phenomenon is of significance for the epistemology of introspection-and, even if it is, it doesn't seem possible to fail to understand those words: to misidentify the content or force of an utterance in inner speech. ${ }^{40}$ At most, one can misidentify the words, or other symbols, that figure in one's (inner) utterance — as when, upon speaking out loud one realizes that one wasn't thinking in the language one took oneself to be thinking in. (Note also that evidence of such misidentification doesn't defeat one's introspective warrant to believe that one thought such-and-such.)

Misleading evidence can undermine too. But once again: what would it look like? On the face of it, any such evidence would have to include - or operate against the backdrop of-evidence that the controversial view of introspection just outlined is correct. Let's give our agent that; then perhaps, in light of further details, it could be rational for her to think that relevant communication-failure has indeed occurredsay, that she's misunderstood a crucial inner utterance. (Apparent expert testimony might suffice.) That, in turn, might undermine her introspective warrant to believe that she said that $p$-and, derivatively, her warrant to believe that $p{ }^{41}$

But if that's what it takes, it takes too much. It is not enough to point to cases where there's reason to believe a substantive, controversial claim about the etiology of 
introspection-even granted such cases are possible. They're too cheap. To a first approximation: for any class of beliefs $c$ and method $m$, such that it's possible to have (sufficient) evidence that one's $c$-beliefs are formed or sustained at least partly by $m$, there's a set of possible underminers - a set of first-order considerations that, for anyone who has that evidence, are able to constitute underminers (of whatever warrant her $c$ beliefs do, or would, enjoy). So, to make good on the present suggestion, we need to come up with a cleaner example: a cleaner example where the purportedly testimonial warrant/knowledge is vulnerable to defeat by evidence of communication-failure (as well as by evidence of insincerity and of incompetence). I can't think of one.

I've given Neta's proposal my best shot. The most it can do is help explain a certain kind of warrant/knowledge that arguably doesn't qualify as testimonial. And if it were testimonial, it would be self-testimonial. The proposal could still be used in a vindication of A Priori Testimony-but it would be a vindication with the somewhat disappointing rider that what makes the thesis true is that a certain kind of selftestimony is sometimes a priori. Furthermore, what does the explaining of the agent's warrant/knowledge, in the most favorable case, is her a priori warrant to believe that she, or her source, said that $p$-at no point need her (derivative) a priori warrant to believe that someone at some point said that $p$ be mentioned. I haven't even tried to make good on the claim that there are (at least some, actual) cases where she only, somehow, has the latter warrant—and partly on that basis knows that $p .{ }^{42}$

\section{4}

\subsection{Enablers and explainers}

Let's return to the argument rehearsed in $\$ 2.2$ (my second objection to Burge). I argued that a successful recipient's empirically warranted belief that her source said that $p$ plays a certain epistemic role vis-à-vis her testimonial belief that $p$-that of a ground, or base - a role that, on the face of it, can't be reconciled with A Priori Testimony. Pending a reconciliatory story, we are owed a plausible description of a case where it doesn't play that role-a case that, nevertheless, instantiates testimonial knowledge. It doesn't look promising to model the case on stock examples of reasonindependent causation. But it's not clear what the alternative is, once we grant that the recipient's belief about what's said both provides a reason for her to believe that $p$, and partly causally explains that belief.

As stated, the objection assumes that any successful recipient is warranted in believing that her source said that $p$. Can it proceed on the weaker assumption that she has warrant to believe or for believing this (i.e. 'propositional' warrant)? On the weaker assumption, it's left open whether her belief about what's said explains her testimonial belief (since it's left open whether she has the former). Would it, still, be dubious to suppose that there are 
cases where the proposition that her source said that $p$ isn't among the reasons for which she believes that $p$ ?

Arguably not - at least not on the grounds that it forces a peculiar picture of what goes on in her mind. For all that's been said, these are simply cases where the causalexplanatory constraint on basing is violated in a straightforward way: there's no need to invoke anything like deviance. If there's no such constraint on basing, more must be said of course. But there seems to be nothing inherently problematic about cases of roughly this shape: an agent knows or has warranted belief that $p$; she also has a reason to believe that $q$; $q$ is (or would be) a reason for her to believe that $p ; q$ isn't among the reasons for which she believes that $p$. Perhaps the critical type of testimony case is just another case like that?

Fair enough. The argument is conditional on the stronger assumption (which, importantly, I have yet to see a compelling counter-example or objection to ${ }^{43}$ ). However, there's a residual issue that cries out for explanation-one that can't be avoided by retreating to the weaker assumption-namely: why does testimonial knowledge/warranted belief that $p$ require warrant to believe that one's source said that $p$, if not because it rests, in part, on that warrant? (And, if it does, how could it ever be a priori?) If there's another-better-explanation available, it would be good to see what it looks like. Now, if both assumptions—strong and weak-are abandoned, that pressure goes away as well. But another emerges: to explain the three-prong defeater-pattern that seems to be characteristic of testimonial warrant and knowledge; in particular, the vulnerability to defeat by evidence of insincerity and communicationfailure. The assumption - either strong or weak — points to a straightforward explanation of that vulnerability. ${ }^{44}$

Someone who grants the stronger assumption might object at a different point: to the claim that the recipient's belief about what's said plays a causal-explanatory-as opposed to causal-enabling - role vis-à-vis her testimonial belief. This distinction (too) is hard to explicate, but not to illustrate. For instance, that Bettie has a head is plausibly a causal enabling condition, relative to a specific ordinary context, and the explananda that she likes chocolate cake: it's part of the general background conditions that make this possible, but it doesn't explain, even in part, why or how it happens. (Perhaps it could explain it, in other-rather peculiar-circumstances; that doesn't affect the point.)

This distinction is different from-and, it seems, crosscuts—-that between warrantenablers (states/conditions in the warrant-enabling role) and warrant-conferrers (states/ conditions in the warrant-conferring role). ${ }^{45}$ Enablers, in the second sense, can be causal explainers, and so far I've been assuming that that's precisely the status that the A Priori Testimony advocate would assign to the successful recipient's belief that her source said that $p$, relative to her belief that $p$.

Note that it's indeed what we should say, if we wish to sustain the analogy with the case of the logic proof. (Unlike, say, the rotation of the earth, and the absence of too much arsenic in your system, your perception of the representation of the proof partly 
causally explains your knowledge of the theorem.) Furthermore and importantly, the alternative has no intuitive support.

A plausible intuitive mark of genuine causal enablers is that they're legitimately taken for granted in a satisfying, causal or other, explanation of the given effects (cf. Bermùdez 1995). We can give a complete (correct) account of why Bettie likes chocolate cake, without at any point citing her having a head. ${ }^{46}$ Another intuitive mark is that causal enablers tend to stay constant across a large amount of (actual and counterfactual) variation in the effects they enable-presumably that's why they're legitimately ignored, in the explanation of these effects. (And why they have little, if any, predictive force on their own.) Other things equal Bettie would still have a head, whether or not she liked chocolate cake-indeed, whether she had any food preferences at all.

But the successful recipient's belief that her source said that $p$ isn't legitimately ignored in the explanation of her believing that $p$ by testimony (under that - the relevant-description). How would the explanation go? It might of course be overdetermined that a given recipient believes that $p$, or even that she believes that $p$ by testimony, but that's beside the point: for each testimonial route, the fact that she believes that her source said that $p$ is a crucial part of the explanation. Relatedly, there's little reason to think that her belief about what's said exhibits the constancy of a causal enabler (vis-à-vis significant variation in the purported 'enablee'): that, other things equal, she'd still believe that her source said that $p$, whether or not she believed that $p$ rather than not- $p$, or $q$, or nothing at all-by that source's testimony. Again, obvious enablers (of her believing that $p$ by testimony) include her having a head, and the absence of too much arsenic in her system: these conditions do pass the test. ${ }^{47}$

\subsection{Fast track warrant preservation}

Here's a final suggestion (on my opponent's behalf).

Let's concede that any successful recipient of testimony that $p$ is warranted-empirically warranted-in believing that her source said that $p$, and on that basis empirically warranted in believing that $p$. At least some such recipients are also warranted in believing that $p$ on independent, a priori grounds. What grounds? Those of her source. The source's warrant sometimes takes the 'fast track', alongside the recipient's empirical grounds for believing the same proposition-it's robustly preserved in the testimony, status and strength intact. If it's a priori, of sufficient strength, and not itself testimonial, the recipient can even gain a priori knowledge that $p$ in this way.

In the abstract, this model - the 'Fast Track Model'-is at least not wildly implausible. It can be regarded as a (substantial but) friendly amendment to Burge's account, or as part of a competitor; this does not matter. (It's clearly compatible with many different views of the 'slow' track.) It's a model on which all-things-considered testimonial warrant is never a priori, but that's not a problem per se: doxastic warrant, even knowledge, could be over-determined in the critical cases. The model gives the advocate of A Priori Testimony recourse to the natural picture of the recipient's 
psychology outlined in $\$ 2.2$ - with the added proviso that the natural picture isn't always the whole picture. Note also that the model doesn't give us 'more than we bargained for' (cf. §1.2): testimony only issues a priori warrant when the source (or, perhaps, the source's source...) has a priori, non-testimonial warrant. And in the absence of a source, or a source with warrant, there'll be no a priori warrant by testimony, since there's no warrant (of any kind) to be preserved. ${ }^{48}$

However, a proponent of the Fast Track Model faces two challenging, preliminary tasks: to clarify the intended warrant-preservation thesis, and to articulate the mechanism that implements it - the separate mechanism that explains how warrant is indeed preserved, in the intended sense, if/when it is. (The preceding arguments should make clear why a separate mechanism is called for. But, surprisingly, that need seems to have been overlooked so far. ${ }^{49}$ ) I'll focus on the former task, since it seems prudent to address that first (and precisify the job description for the mechanism). Moreover, we don't in fact have a serious proposal on the table until the warrant-preservation thesis at issue has been clarified.

There's a range of warrant-preservation (or 'transmission') theses in the general vicinity that don't meet the Fast Track Model's needs-including variations on each of the following:

A recipient has warrant for believing that $p$

(a) if and only if the source has warrant for believing that $p$

(b) only if the source has warrant for believing that $p$

(c) if the source has warrant for believing that $p$

(d) if and because the source has warrant for believing that $p$

(e) in some cases where the source has warrant for believing that $p$.

Options (a) through (d) are too weak and too strong — at any rate: considerably stronger than the model needs, and arguably too strong to be plausible-whereas (e) is just too weak. Each option is too weak, in that it leaves it entirely open whether the recipient's warrant shares any significant features with the source's warrant — notably: that of being a priori (or a posteriori, as applicable).

What the Fast Track Model needs is a thesis of roughly the following form:

A successful recipient has warrant of type $w$ for believing that $p$

(f) if (alt. if and because) the source has warrant of type $w$ for believing that $p$

(g) in some cases where the source has warrant of type $w$ for believing that $p$.

The restriction to successful recipients allows us to say that the other-the unavoidably empirical - strand of any all-things-considered testimonial warrant doesn't stand or fall with the source's warrant. Furthermore, it's built into each of (f) and (g) that, when warrant is preserved, the recipient has the same warrant (type) as the source. On the intended interpretation, warrants are rather finely individuated, but not too finely: not so finely that two distinct subjects are unable to share warrant type, and not so broadly that two warrants of the same type can differ in their status as a priori or as a posteriori. 
(Nor in strength - at least not too much-lest the explanation of a priori testimonial knowledge fall through.) Now: what's that way? Can anything more informative be said about it?

Perhaps, on the intended reading, warrants are just carved in whatever way they're carved for it to be possible to pass on one's warrant to another in the usual, seemingly un-mysterious, way: by facilitating her access to it. I can share my (a priori) warrant for believing a certain logical theorem with you, by guiding you through the proof-or, on suitable assumptions about your motivation and ability, simply by informing you that there is a proof, and leaving you to it. Likewise, I can share my (a posteriori) warrant for believing that Bettie likes chocolate cake, by telling you that she eats it every day and claims to like it —or perhaps by pointing over at Bettie (fully occupied eating cake).

Whatever the precise structure of my warrant, and however exactly that structure differs from that of relevantly different warrant types, there's an intuitive sense in which I'm able to pass you my warrant—and share it with you — in examples like these. And when a warrant is shared in this familiar way, then, other things equal, it doesn't lose its a priori/a posteriori status 'in transfer'. Provided you pick up on the right warrant - the warrant I attempt to share-and you lack defeaters (and status-affecting defeaterdefeaters), the warrant you have as a result of our interaction is a priori if mine is, and a posteriori if mine is. The same goes, it seems, for relative strength: other things equal, our warrants will match in that respect too. (The status and strength of our allthings-considered warrants may, of course, differ-but that, too, is as it should be.)

Let's call this phenomenon 'facilitating warrant-sharing.' It might be tempting to use it as the blueprint- the blueprint for further explication of the warrant-preservation thesis at the heart of the Fast Track Model. Since we have an intuitive, independent grasp of facilitating warrant-sharing - and so, presumably, of the individuation conditions for warrant types that's implicit in it-it might be tempting to invoke it here. Note also how plausible it is that, in facilitating warrant-sharing, one's experiences of the other agent's utterance, of specific features of the conversational context, etc., just play a triggering role (vis-à-vis the warrant one acquires). Perhaps, then, the possibility of a priori testimonial warrant can, after all, be explained with appeal to the proof case analogy?

However, there's a problem right upfront: in facilitating warrant-sharing, too many features of the original warrant seem to survive the transfer from one agent to the next - too many for it to be a suitable blueprint. In particular: actual and potential defeaters survive-including underminers (at all levels of grain). Other things equal, the warrant you have, after I guide you through the proof, or alert you to cake-eating Bettie, is vulnerable to the same undermining defeaters as my warrant is: if evidence that Bettie suffers from bulimia nervosa potentially undermines my warrant for believing that she likes chocolate cake, it potentially undermines yours; if evidence that the ostensible proof we worked through contains a serious but elusive fallacy poten- 
tially undermines my warrant for believing the theorem, it potentially undermines yours-and so on.

But these defeater-patterns don't survive the transfer of warrant that supposedly takes place in testimony. To see this, suppose you and I are warranted in believing the same proposition — say, that many children have imaginary friends - by the testimony of two different sources, Max and Bettie, respectively. They're warranted, in turn, but by different methods: Max's warrant partly rests on his warrant to believe that this was confirmed by a recent global study; Bettie's warrant partly rests on her warrant to believe that Where the Wild Things Are is hugely popular.

Presumably, the case can be elaborated in such a way that the epistemic situations of the recipients (i.e. you and me) don't differ in any (other) relevant respects-say, with respect to what we believe, or have reason to believe, about our sources' warrants.

On the proposed gloss, the warrant-preservation thesis seems to imply that our respective, testimonial warrants would, nevertheless, have starkly different defeaterstructures: not just in that yours (and not mine) is potentially undermined by evidence that Max's utterance was insincere, that Max is incompetent, etc. - that's how it should be; but in that yours (and not mine) is potentially undermined by evidence that the study Max relies on has methodological flaws, or has been disconfirmed by other studies in the interim. Conversely, of course, for my warrant and Bettie's: other things equal, my warrant inherits the defeater-pattern associated with hers. But that's very implausible. ${ }^{50}$ (And the choice between (f) and (g) makes no relevant difference. Against (g): just add whatever's supposed to be missing, for the case to be one where warrant is indeed preserved; then, again, consider the upshot for the distribution of defeaters.)

If this is right, then warrants, as they figure in the warrant-preservation thesis that the Fast Track Model needs, aren't individuated in whatever way warrants are individuated in facilitating warrant-sharing. (Or they are, and the view is a non-starter.) But how, then, are they individuated? Without an informative answer to that question, the warrant-preservation thesis-and with it the Fast Track Model-is simply too programmatic to deserve our confidence. ${ }^{51}$

\section{Notes}

1. Unless indicated, all the references in this section are to works by Burge.

2. See my 2006, §9, for some discussion of the other analogy-with so-called 'preservative memory'. (See also Christensen and Kornblith 1997; Lawlor 2002.)

3. If Kitcher 2000 or Williamson 2007 is right, we may not. But I won't engage their arguments here. (See my 2011, §9 for some discussion of Williamson's.)

4. Nothing here turns on how exactly this distinction is precisified. For discussion, see Silins 2006; Casullo 2007a.

5. Burge uses 'a priori' and 'non-empirical' interchangeably; likewise for 'a posteriori' and 'empirical'. I follow that usage. And I treat 'warrant', 'evidence', and (good, epistemic) 'reason' as equivalent. When nothing hinges on the difference, I move freely between ' $S$ 


\section{I8O ANNA-SARA MALMGREN}

has warrant to believe/for believing that $p$ ' (propositional warrant) and ' $S$ is warranted in believing/has warranted belief that p' (doxastic warrant). Most of the time I write as if belief, as well as warrant, is an all-or-nothing affair-this, too, is a simplification that nothing turns on.

6. In section 3 we return to the question what, besides assertion, might fall in the umbrella category.

7. A little more precisely: all it takes is that she's a linguistically competent, rational agent, who lacks defeaters. According to Burge, the source of the u-entitlement is the reliability of our linguistic competence, whereas the r-entitlement 'comes with being a rational agent'; 1993, 467; 1997, 31; 1999, 233. (For a fuller picture, cf. 2003.)

8. What Burge means by 'standing linguistic competence' is at least roughly equivalent to what some have called 'semantic (or narrow semantic) competence', 'knowledge of the meaning of expression-types', or 'knowledge of context-invariant meaning.' (In 1999, 'comprehension' is used in lieu of 'intellectual understanding'.)

9. Perhaps it's enough that there's a priori non-testimonial knowledge somewhere in the chain. (Either way, it's unclear whether this condition is well motivated, given that Burge's official reason for requiring knowledge by the source is to preclude Gettier-cases; 1993, 486, fn. 24. For related discussion, see Casullo 2007b.)

10. At least for agents relevantly like us — without telepathic capacities, 'thought-injection' skills (cf. 1999, 240), or the like. (Cf. the curious example in Burge 1999, 240.) But it's not clear to me that our notion of testimonial warrant/knowledge is even applicable to agents with such radically different means of communication.

11. This qualification will henceforth be treated as understood.

12. What is controversial is that at least part of her overall warrant to believe that content is default warrant - and, of course, that it's sometimes a priori.

13. Another way is by testimony, but I trust that it's clear why appeal to that route would be a non-starter here.

14. See Malmgren, 2006, 217, fn. 40. Note also that Burge's argument for the claim that perception sometimes plays a triggering role, vis-à-vis the u-entitlement, doesn't bear directly on this concern: even if that argument were successful-as I argue that it's not (2006, 201-2) - the most it would show is that the u-entitlement is sometimes a priori. The question how it could be remains.

15. But see my 2006, 217-18 (esp. fn. 41).

16. The remaining options that I offer Burge - that the u-entitlement (just like the r-entitlement) is a warrant to believe that $p$, or that it's a warrant to make a transition-are criticized in my 2006, §5, and there's no need to go over them here.

17. It's plausible that the requirement is conditional on the possession of certain concepts (cf. my 2006,236, n. 79). And that what in the first instance matters is the apparent saying and source.

18. I write as if what does the causal work is strictly speaking her beliefs, rather than her warranted beliefs or knowledge, but nothing crucial turns on this. Likewise for various general issues in the metaphysics of causation-e.g. whether mental states of any kind (as opposed to, say, facts or events) are fit to be causal relata-and in the metaphysics of reasons/warrants. The argument can be restated in your framework of choice.

19. I don't think it matters whether we think of the relevant contextual factors as including auxiliary reasons, or only warrant-enablers - conditions that enable the given proposition to constitute a ('complete') reason. 
20. E.g. Williamson 2000. (But, by my lights, knowledge of what's said is at most a plausible requirement on testimonial knowledge.)

21. For a helpful overview, see Korcz 2010.

22. See e.g. Davidson 1963; Chisholm 1966; Lennon 1990; Plantinga 1993.

23. This gloss - in particular the notion of normality involved — obviously needs precisification. But it's not meant to rule out the possibility that, for some agents and effects, interference mechanisms are statistically dominant.

24. I leave counterfactual analyses of the basing-relation out of consideration (see e.g. Swain 1979) since, on the face of it, they have nothing at all to say about the present case: all relevant counterfactuals hold.

25. At least: not warranted by the route that's explicit in the description of each case. (Cf. §4.)

26. The difference in formulation makes no difference; in particular, 'rational' here contrasts with 'arational'-not 'irrational'. (But see Fricker 2006 for a case that Burge in fact equivocates on the notion of rationality at play.)

27. Nothing controversial is intended by 'introspective'-all we need is that there's at least one type of warrant, that's available to the first person (only), that's a priori, and that at least has the scope indicated in the text. (And we can ignore the possibility that whether it's available depends on the value of $p$.)

28. I.e., that a 'liberal' treatment of the warrant-structure is correct. Strictly speaking, the argument only requires that no additional, empirical warrant is called for (and the brand of 'conservatism' on which that's true is radical indeed - given the simplicity of the argument under consideration, it's unclear if it can recognize any inferential a priori warrant at all).

29. In correspondence Neta suggests a route from it introspectively 'seeming' that someone at some point said that $p$ (to having a priori warrant to believe that someone did). It's not clear how exactly the purported seeming-state is supposed to differ from a belief (or memory) state with the same content, but in any case this suggestion falls in the same category as those listed in the text: in effect, it just transforms my original request-for an explanation of how it's possible to have a priori warrant to believe the target claim-to a request for an explanation for how the proposed transition could be a priori (in the terminology of my 2006, 220-4).

30. It's also worth noting that the kind of a priori warrant that the agent has, on my reading of the case- a partly introspective, inferential, warrant - is most likely not what Burge himself had in mind. (For one thing, it makes the restriction to contents that can be intellectually understood' completely mysterious. For another, it jars with his repeated insistence that the warrant at issue is non-inferential-perhaps even with it being an entitlement! Cf. Burge 1997, 30.) But I'm interested in the proposal as a suggestion on Burge's behalf: one that might be used to amend or modify his account, with a view to vindicating A Priori Testimony.

31. I gloss over differences in the requirements for (testimonial) warrant and knowledge. Nothing turns on this.

32. Pace some versions of the 'reflection principle' (van Fraasen 1984). The intuitive considerations that I offer here don't yet amount to-and aren't meant to be-an argument against that principle. (But see e.g. Christensen 1991; Arntzenius 2003).

33. Certain permutations may survive, of course. (This won't matter here.) Examples of each type of gloss can be found in Matilal and Chakrabarti 1994; Lackey and Sosa 2006. 
34. E.g. Graham 1997; Lackey 2006; Cullison 2010. (Contrast the approach of Fricker 2006a.)

35. The notion wouldn't have to be pre-theoretical—and I'm not assuming that. Why think that there is a determinate notion even within philosophical discourse that meets these desiderata?

36. Roughly: defeaters that provide evidence that the method whereby the agent formed, or would form, her belief that $p$ isn't a good method-e.g. that it's unreliable. 'Rebutters,' in contrast, provide independent reason to disbelieve $p$. (This is rough indeed, but should suffice for our purposes. Cf. Pollock 1986; Casullo 2003).

37. The hypothesis isn't, implausibly, that it's impossible for non-testimonial warrant/knowledge to exhibit the relevant defeater-pattern; but that doing so is necessary to count as testimonial warrant/knowledge in particular - that it's part of the nature or essence of that epistemic kind.

38. E.g., for each defeater-type, the evidence may pertain to a single case, to any possible case, or anything in between. And evidence concerning the de facto source arguably only undermines (testimonial) knowledge, whereas evidence concerning the apparent source undermines both warrant and knowledge. ('Trustworthiness' is sometimes used as an umbrella term for sincerity and competence.)

39. I'm assuming that introspective warrant is defeasible in the first place. (For dissenting voices, see e.g. Alston 1972; Burge 1996.)

40. But cf. Byrne 2005. (The point is orthogonal to whether we-also, always-think in a language-of-thought.)

41. A parallel move might be available for the second type of underminer.

42. Neta also addresses another argument of mine, strictly aimed at the suggestion that the $\mathrm{u}$-entitlement (just like the r-entitlement) is a warrant to believe that $p$ (my 2006, 210-11). That suggestion implies that a recipient can have a priori warrant for believing contents that her source doesn't - indeed can't-have a priori warrant to believe. That struck me as absurd. I first illustrated the perceived absurdity with a case featuring the content that it's raining. Neta complains that that content isn't capable of being intellectually understood (cf. $\S 1.2)$. But I explicitly considered that possibility, later in the text, and went on to give other examples (my 2006, 224). Neta's main point, however, is that he simply doesn't find the implication in question absurd. And that's fair enough: as I also acknowledged (ibid. 225), it's in any case a consequence of Burge's overall view-it's what explains the expansion of the domain of a priori warrant - and one might just regard it as another (perhaps surprising or interesting) upshot of that view. In this chapter, I've tried to articulate at least my own unease with this consequence a little better (\$1.2). And fortunately not much hinges on treating it as absurd; there are other reasons to reject the suggestion this argument was aimed at (my 2006, 218-19).

43. There are many variables, and it's hard to construct a clear test case (cf. my 2006, 229-30, esp. n. 66). But extant attempts at counter-examples tend to assume a very stringent conception of belief, or of the psychological processes involved (e.g. Burge 1993; Recanati 2002; Audi 2006). Goldberg 2010 assumes an implausible account of the warrant structure (68). Gilbert 1991 argues, on partly empirical grounds, that it's impossible to "understand a proposition without representing it as true" (114). Taken at face value, that's obviously false, since there are world-to-mind directed propositional attitudes (e.g. desires). Taken more charitably — as the claim that belief necessarily precedes disbelief (temporally and/or 
explanatorily)—it's compatible with everything I'm saying. (At most, however, Gilbert's arguments support the even weaker claim that people are rather gullible.)

44. The significance of incompetence is also easily explained, on the overall model I favor (my 2006, §8).

45. The standard terminology here is confusing - the same phrase, 'causal enabler', is sometimes used to designate enabler-as-opposed-to-justifier, and other times to designate enabler-asopposed-to-explainer. (And neither distinction maps neatly on to the efficacy/relevance distinction.)

46. Perhaps there are several correct explanations, at different levels of description; nothing here turns on this.

47. Interestingly: her beliefs that there are other minds, that she's not a brain-in-a-vat, that she's not now dreaming, etc., seem to pass the test too-given some obvious restrictions on the value of $p$.

48. The model also avoids the undesirable consequence that, unless there's a source, and that source has warrant, there's no testimonial warrant at all—a consequence that seemingly can't be avoided if all testimonial warrant is explained in terms of warrant-preservation. (For a bold endorsement, see Owens 2006, 16.)

49. Not just by Burge, but e.g. by Faulkner 2000, Moran 2006, Owens 2006, Schmitt 2006each of whom advocates a warrant-preservation thesis of roughly the kind the model requires. Lawlor 2002 notes the need, as well as the corresponding need in an account of warrant-preservation by memory; she argues that it can be met in the latter case, but not in the former. (However, the mechanism Lawlor describes at most explains the preservation of content, by memory - but that's not sufficient for warrant-preservation, and arguably not necessary either.) Goldberg 2010 specifies a mechanism of sorts. But see my 2012 for objections.

50. If there's a strength-asymmetry between our sources's warrants, the thesis also implies that we're warranted to different degrees. That, too, seems to me unacceptable. But it's a consequence that the Fast Track Model is supposed to have. If anything, then, this is the basis for a different objection. (And intuitions about warrant-strength seem to vary considerably.) For examples similar to mine, see McDowell 1994; Gerken 2011.

51. Many thanks to audiences at Amherst College, Harvard, Northern Institute of Philosophy at Aberdeen, the Carolina Metaphysics Workshop, and to Mikkel Gerken, Mike Raven, and Ram Neta.

\section{References}

Artzenius, Frank, 2003, "Some Problems for Conditionalization and Reflection," Journal of Philosophy, 100 (7), 356-70.

Audi, Robert, 2006, "Testimony as an A Priori Basis of Acceptance: Problems and Prospects," Philosophica, 78, 85-104.

Bermùdez, Jose Luis, 1995, "Nonconceptual Content: From Perceptual Experience to Subpersonal Computational States," Mind and Language 10 (4), 333-69.

Burge, Tyler, 1993, "Content Preservation," The Philosophical Review, 102, 457-88.

Burge, Tyler, 1997, “Interlocution, Perception, and Memory,” Philosophical Studies, 86, 21-47. 
Burge, Tyler, 1999, "Comprehension and Interpretation," The Library of Living Philosophers, 27, The Philosophy of Donald Davidson, ed. Lewis E. Hahn, 229-54. Chicago: Open Court.

Burge, Tyler, 2003, "Perceptual Entitlement," Philosophy and Phenomenological Research, 67, 503-48.

Byrne, Alex, 2005, "Introspection," Philosophical Topics, 33 (1), 79-104.

Byrne, Alex, "Knowing That I Am Thinking," forthcoming, Self-Knowledge, ed. A. Hatzimoysis. Oxford: Oxford University Press.

Casullo, Albert, 2003, A Priori Justification. New York: Oxford University Press.

Casullo, Albert, 2007a, "What is Entitlement?" Acta Analytica 22 (4), 267-79.

Casullo, Albert, 2007b, “Testimony and A Priori Knowledge," Episteme 4 (2007): 322-34.

Chisholm, Roderick, 1966, Theory of Knowledge. Englewood Cliffs, N.J.: Prentice-Hall.

Christensen, D., 1991, "Clever Bookies and Coherent Beliefs," The Philosophical Review, 100, 229-47.

Christensen, David, and Hilary Kornblith, 1997, "Testimony, Memory, and the Limits of the $A$ Priori," Philosophical Studies, 86: 1-20.

Coady, C. A. J., 1992, Testimony; A Philosophical Study. Oxford: Clarendon Press.

Cullison, Andrew, 2010, "On the Nature of Testimony," Episteme, 7 (2), 114-27.

Davidson, Donald, 1963, “Actions, Reasons, and Causes," Journal of Philosophy, 60.

Evans, Gareth, 1985 [1979], "Reference and Contingency." In Collected Papers. Oxford: Clarendon.

Faulkner, Paul, 2000, “The Social Character of Testimonial Knowledge," Journal of Philosophy, 97, 581-601.

Fricker, Elizabeth, 2006, "Second-Hand Knowledge," Philosophy and Phenomenological Research, 73 (3), 592-618.

Gerken, Mikkel, 2011, "Internalism and Externalism in the Epistemology of Testimony," Philosophy and Phenomenological Research (DOI 10.1111/j.1933-1592.2011.00532.x).

Goldberg, Sanford, 2010, Relying on Others. Oxford: Oxford University Press.

Graham, Peter J., 1997, "What is Testimony?”, The Philosophical Quarterly, 47, 227-32.

Green, Christopher R., 2008, "Epistemology of Testimony," Internet Encyclopedia of Philosophy, ed. Dowden and Fieser.

Kitcher, Philip, 2000, "A Priori Knowledge Revisited," New Essays on the A Priori, ed. Boghossian and Peacocke, 65-91. New York: Oxford University Press.

Korcz, Keith Allen, 2010, "The Epistemic Basing Relation," The Stanford Encyclopedia of Philosophy, ed. Zalta.

Lackey, Jennifer, 2006, “The Nature of Testimony,” Pacific Philosophical Quarterly, 87, 177-97.

Jennifer Lackey and Ernest Sosa (eds), 2006, The Epistemology of Testimony. Oxford: Oxford University Press.

Lawlor, Krista, 2002, "Memory, Anaphora and Content Preservation," Philosophical Studies, 109: 97-119.

Lennon, Katherine, 1990, Explaining Human Action. London: Duckworth.

Malmgren, Anna-Sara, 2006, "Is There A Priori Knowledge by Testimony?", The Philosophical Review, 115: 2, 119-241.

Malmgren, Anna-Sara, 2011, "Rationalism and the Content of Intuitive Judgments," Mind 120: 263-327. 
Matilal, Bimal Krishna and Chakrabarti, Arindam, 1994, Knowing from Words: Western and Indian Philosophical Analysis of Understanding and Testimony. Dordrecht and Boston: Kluwer Academic. McDowell, John, 1994, "Knowledge By Hearsay," in Matilal and Chakrabarti, 1994.

Moran, Richard, 2006, "Getting Told and Being Believed," in Lackey and Sosa (eds), The Epistemology of Testimony, Philosophers' Imprint 5: 4.

Neta, Ram, 2010, "Can A Priori Entitlement be Preserved by Testimony?” in Haddock, Millar, and Pritchard (eds) Social Epistemology. Oxford: Oxford University Press, 194-215.

Owens, David, 2006, “Testimony and Assertion,” Philosophical Studies, 130: 105-29.

Pollock, John, 1986, Contemporary Theories of Knowledge. Savage, MD: Rowman and Littlefield.

Recanati, F., 2002, “Does Linguistic Communication Rest on Inference?” Mind and Language, 17 (1-2): 105-12.

Schmitt, Frederick F., 2006, “Testimonial Justification and Transindividual Reasons,” in Lackey and Sosa, 2006.

Silins, Nicholas, 2012, "Explaining Perceptual Entitlement," Erkenntnis, 76 (2): 243-61 (DOI 10.1007/s10670-011-9304-0).

Swain, M., 1979, "Justification and the Basis of Belief," in Pappas (ed.), Justification and Knowledge, Dordrecht: D. Reidel.

Van Fraassen, B. C., 1984, "Belief and the Will," The Journal of Philosophy, 81, 235-56.

Williamson, Timothy, 2000, Knowledge and Its Limits. Oxford: Oxford University Press.

Williamson, Timothy, 2007, The Philosophy of Philosophy. Oxford: Blackwell. 